\title{
Correction to: Fraction of high-grade cervical intraepithelial lesions attributable to genotypes targeted by a nonavalent HPV vaccine in Galicia, Spain
}

S. Perez ${ }^{1 *}$, A. Iñarrea², R. Pérez-Tanoira ${ }^{3}$, M. Gil ${ }^{2}$, E. López-Díez ${ }^{4,8}$, O. Valenzuela² ${ }^{2}$ M. Porto ${ }^{2}$, L. Alberte-Lista ${ }^{5}$, M. A. Peteiro-Cancelo ${ }^{5}$, A. Treinta' ${ }^{1}$ R. Carballo ${ }^{1}$, M. C. Reboredo ${ }^{2}$, M. E. Alvarez-Argüelles ${ }^{6}$ and M. J. Purriños ${ }^{7}$

\section{Correction}

After publication of the article [1], it was brought to our attention that the author E. López-Díez is missing their second affiliation. The author would also like to indicate an affiliation to "Universidade de Vigo, Pontevedra, Spain".

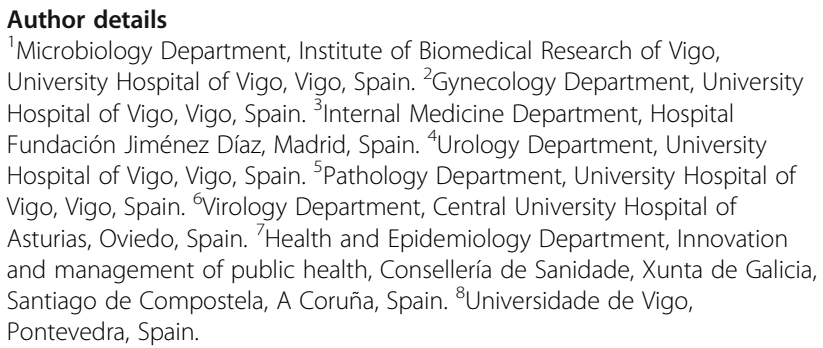

Received: 27 February 2018 Accepted: 1 March 2018

Published online: 06 March 2018

\section{Reference}

1. Perez S, Iñarrea A, Pérez-Tanoira R, Gil M, López-Díez E, Valenzuela O, et al. Fraction of high-grade cervical intraepithelial lesions attributable to genotypes targeted by a nonavalent HPV vaccine in Galicia, Spain. Virol J. 2017;14:1. https:/doi.org/10.1186/s12985-017-0879-1.

\footnotetext{
* Correspondence: sonia.perez.castro@sergas.es

'Microbiology Department, Institute of Biomedical Research of Vigo,

University Hospital of Vigo, Vigo, Spain
} 